\title{
Moderating Effect of Institutional Policy on Institutional Strategies and Performance of Selected MDIs
}

\author{
OTSUPIUS, Anthonia Ighiebemhe (PhD) \\ Department of Business Administration, Faculty of Arts, Management \& Social Sciences, Edo State University Uzairue, \\ KM7, Auchi-Abuja Expressway, Iyamho, Edo State, Nigeria
}

\begin{abstract}
This research attempt to address the question, can it be inferred that institution policy has effect on the relationship between institutional strategies and the performance of the selected MDIs in Nigeria? Despite the importance of Institutional Strategies (IS)-(Agility, Flexibility, Alliance, and Planning), as identified strategic options/approaches used by management development institutions (MDIs) to pilot the different setting towards attaining a successful performance. The multi-stage sampling technique was used to select 398 staff. Stratified sampling technique was used to select the relevant MDIs across the entire MDIs in Nigeria.
\end{abstract}

Data were collected using a validated questionnaire. Data were analyzed using descriptive and inferential (correlation and regression) statistics to determine the moderating effect of institution policy on the relationship between IS and performance of the selected MDIs.

Findings revealed that institution policy had no statistically significant moderating effect on the relationship between IS and performance of the selected MDIs in Nigeria, $\left(\right.$ Adj. $R^{2}=.137$, $F_{(4,336)}=0.933, p>.05$. The study concluded that recognizing the role and importance of MDIs in economic development, it is recommended that government (the office of the head of civil service of the federation) should develop flexible and concise policies as means of institutional support. When policies are understood by the different entities in an institution, there will be an atmosphere of improved performance reason being that everyone will work according to stipulated rules, using their initiative for creative value within the stipulated strategies.

Keywords: Institutional strategies, Management development institutions, Performance, Institution Policy

\section{INTRODUCTION}

$\mathrm{I}$ today's business environment which is characterized by stiff competition and frequent changes in policies, no institution desirous of achieving its goals can afford to carry out its business without developing and adopting appropriate strategies. Ojokuku and Adegbite (2014) noted that any performing Management Development Institution (MDI) should be able to impact on their clients the following ways. The ability to do what it's already doing in a new way (in the form of new knowledge, skills and management capabilities) in services delivery capacity, enhancing the capacity to grow (expansion), and environmental consciousness and sensitivity; that is, the ability to sense the needs for change and respond to them (adaptive strategy). Ability to execute these factors successfully requires the understanding, adoption and practical use of adequate strategy (ies) needed to achieve high performance levels over time. According to Eniola and Ektebang (2015), an organization should formulate and implement strategies that will lead to superior performance in relation to other competitors in the same sector.

In a complex environment such as Nigeria, most public institutions evolve, collide and split (Onyema \& Akanbi, 2012). One of the primary determinants of public institutions' success is strategic planning because; the competitive landscape has been shifting in recent years more than ever (Zhao, Qion, Hefu, Robert, \& Liang, 2014). Weber, Junni, Sarala and Tarba (2015) further explained that globalization, rapid technological change, the codification of knowledge, the internet, talent and employee mobility, increased rates of knowledge transfer, imitations, changes in customers' expectations, have all caused the accelerated changes and disruptions in the public training institutions. Even though performance initiatives are evident in the private training institutions and are often well publicized, the quest to find ways to improve performance in government training institutions continues due to lack of deliberate policies and obsolencse of service model (Aremu \& Oyinloye, 2014; Oyedijo, 2012). Similarly, some research studies have reported that poor responds and team efficacy are the foremost challenges of most public training institution fronting over couple of years (Raynor, 2007). This has lead to low subscription/ low rate of participants' subscription due to customers' dissatisfaction.

However, the MDIs to a large extent are faced with bureaucratic regulations on activities and the failure to adopt and incorporate extant policy in discharging their duties has lead to institutional loss of identity (Awais \& Asma, 2013). Similarly, the gap indicates that previous studies on institution policy on MDIs in Nigeria have not addressed the extent to which the extant policy has affected the relationship between adoption of varied strategies and performance of MDIs. Can it then be inferred that institution policy has effect on the relationship between institutional strategies and the performance of the selected MDIs?

Among the major challenges that MDIs has faced in recent years are; as the policy makers, the Office of Head of the 
Civil Service of the Federation (OHCSF), are putting more effort in search for means of improving the performance of MDIs. According to Deloitte Business Day Academy (2009), there is a near complete absence of empirical studies that focus on the institutional strategies and performance of MDIs in the developing economies like Nigeria

\section{LITERATURE}

\section{Institutional policy}

Policy is a vital ingredient in any institution alongside other factors aimed towards the successful attainment of the institutional goals and objectives. It can be seen as a documented development that involves the selection of choices about the most appropriate means to a desired end (Sherri, 2005). According to Jose, Mohammad, Irani and Farhad (2013) in every society, group or institution, there are laws or policies guiding the operations and allocation of resources. However, institutional policy is to ensure an appropriate system in place to realize the vision and mission of the institution and to develop the culture of continuous improvement to help achieve the stated goals and objectives. Similarly, policy can generally be defined as a law, regulatory measure, and course of action, priority concerning a given subject promulgated by a governmental entity or its representatives. Peter and Glyn (nd) viewed policy as a cycle or tool used for analyzing the development of internal and external procedures in place to ensure consistency in performance. It can also be referred to as a strategist approach; it has five stages such as: setting or identification of problem, formulation of policies, and adoption of the policies, the implementation and evaluation. In Policy Based Management System (PBM) (2011), eight step policy cycle are stipulated they include, Issue identification, Policy analysis, Policy instrument development, Consultation, Coordination, Decision, Implementation and Evaluation were also developed.

According to Rahimi and Noruzi (2011) policies are operating rules that can be referred to as ways to maintain order, security, consistency, or otherwise for a goal or mission rather than having to make decisions on a case-by-case basis. Therefore, there are different approaches in institutional policy management especially in today's turbulent ongoing days. This is because the environment changes a lot so policies and policy making strategies always change and become more complicated and sophisticated. Policy based management is one of these strategies approach that is used to simplify the management of a given entity by establishing policies to deal with situations that are likely to occur. From the Policy Library (2011), it was pointed out that institutional policy plays some vital roles in translating values into operations, thereby ensuring compliance with legal and statutory responsibilities guiding the institution towards the achievement of its strategic plan, setting standards; and improving in the management of risk. Also, advocate that a written policy explaining how management relates to and supports the overall mission of the institution should be developed, published and implemented. Such a policy should include guiding principles relating to the emphasis the institution places on the financial and non-financial benefits of the effective management including a strategy as to how these activities should be pursued.

A good and adequate institution policy will make the institution more attractive to partner by providing evidence relating to the institution's expertise in carrying out its functions. For Good practices regarding specific issues, institution should develop and communicate clear incentives for employees who take part in activities. These incentives should be communicated to all existing and new staff and should not only be financial in nature, but also promote career progression including non-academic staff when their inputs are above and beyond their normal responsibilities. Institution should publish a clear conflicts of interest policy in order to ensure that the institution's objectiveness and independence are not affected, and that the institution does not engage in activities which conflict with its basic missions and values (Georg, Erkki, Gillian, \& Leif, 2007).

According to Bureau of Establishments, Management Services and Training office of the Head of Service, (BEMST 2011) Policy is a written document that guides the learning, training and the overall capacity development of a state government, organisation or a country's workforce with its associated legal provisions and regulations. It further explains that such a document can be divided in two main parts such as; the human resource development (HRD) policy issues and the focuses on actual delivery of HR development. Concerning the HRD Policy and the purpose of or mandates of MDIs in Nigeria, at the organisational level, this policy is deemed to cover all public service agencies including all Ministries, Departments and Agencies (MDAs), while at the individual level it covers all personnel in the public service.

The institution's policy mostly includes a long term vision and mission for human resource and capacity development in federal, State Public Service and Local Governments. With clear norms and standards with reference to training (HRD) principles, guidelines and practices. An organizational framework for ensuring appropriate and adequate learning and the provision of training in the Public Service, which will meet the current and future needs of personnel and contribute to the realization of the public service vision, and detailed guidance on the planning, developing, financing, managing and reviewing the implementation of HRD policy.

The policy on actual delivery of HR Development usually include an overall profile of the public service workforce based on HR data analysed. According to agreed criteria including age, gender, grade level, qualification level, particular skills/competences, years of service, and experience.

As part of the focus of this study, identifying the strategies for improved performance of (MDIs) in Nigeria, using institutions' policy as one of the moderating effect; every public servant needs certain core skills to work effectively. At 
grade level 07 the following core skills are required: technical and problem solving skills, people management skills, financial management skills, analysis and use of evidence, programme and project management skills. Micheal, Simon and Jill (2011) described those efforts to improve policy making have varied scale and focus, and have frequently overlapped or seemed to merge with one another. However, four areas has been identified as focus in underpinning the activity. They include: Process: the actions recommended to produce policy, Qualities: the way in which these actions should be carried out by focusing on the characteristics policy should possess, such as being innovative and forward-looking, Structures: The institutional arrangements to support better policy making and Politics: the way in which political aims and desires contribute to policy making.

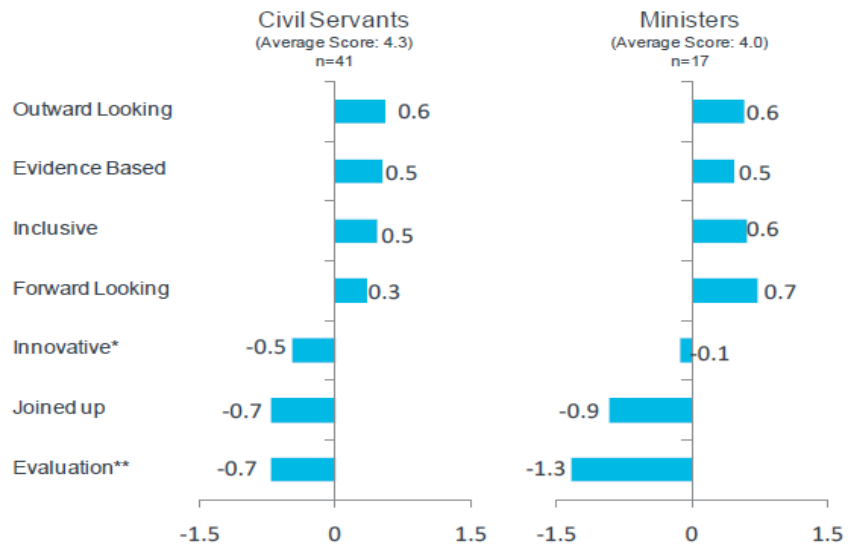

Figure: 1.1: Strengths and weaknesses of policy making characteristics

Source: Micheal, Simon and Jill (2011).

This is based on a survey of former ministers and Civil Servants. The results show the deviation from the average score given for various categories response. Despite how reports aimed at improving policy making, it kept returning to the same issues over the years. There are obvious weaknesses in policy making, that are widely acknowledged and still endure. It is clearly indicated in this report that these problems endure because of systemic barriers. The researcher further attested that the recent attempts to reform policy making have not adequately addressed these barriers-guidance is often effective at detailing what should be done, but not how it should be done.

This was corroborated by a report from Institute for Government Analysis (2010). The report stated the following as the skills that constitute good policy making. The skills framework has two main elements. First, a basic structure of how the policy process was proceeded by (understanding the context; developing the options; getting to a decision; making it happen) and secondly, the themes which need to be considered to deliver successful policy':(the importance of sound evidence as a basis for the policy development; working in a political context; and focusing on the delivery from the outset). Jose, Mohammad, Irani, and Farhad (2013) ascribed social policy primarily to guidelines and interventions for the changing, maintenance or creation of living conditions that are conducive to human welfare. Social policies are education, health, housing, employment and food for all people. Social policy is part of public policy but public policy is more than that, it is an economic policy, industrial policy, and also soial policy. The nature of policy issue is thus relevant not only to scientists and scholars of politics and public administration but also to scholars and practitioners in institutions and organizations of different governments, businesses and NGOs and civil society in general.

Sherri and Torjman (2005) further defined policy as a broad concept that embodies several different dimensions. However, it can be viewed from different perspectives such as:

a. Substantive and administrative policy: refers to policy that is developed within the organization that has responsibility for its implementation.

b. Vertical and horizontal policy: vertical policy is the normal or traditional way in which policy decisions are made within a single organizational structure. It usually starts with broad policy, sometimes called corporate/framework policy. Two or more organizations, and each having the ability or mandate to deal with only one dimension of a given situation develop the horizontal policy. (Smith, 2003)

c. c. Reactive and proactive policy: Reactive policy is made in response to issues that raises concern or crisis that requires urgent attention to avoid general disaster; this is usually common in health and environmental disasters. On the contrast, proactive policy is a deliberately introduced policy which is pursued for a specific choice. This is common in the area of national skills and learning agenda since knowledge and learning have been recognized as vital keys to unlocking both economic and social well-being on any nation.

d. Current and future policy: Current policy is an existing agenda on the public policy document. It is a formal process of amendment or improvement which must also be in place. Contrarily, future policy means non existence of such agenda on the policy document which will require much work to be done in making the policy active.

\section{Institutional Strategies (IS)}

Thomas (1999) developed the concept of institutional strategy because the ability of organizations to strategically influence their environments has become a central concern in organizational research. Therefore, the concept of institutional strategy describes patterns of organizational action that are directed toward managing the institutional structures within which firms compete for resources, or transformation of those structures. Institutional strategy is a comprehensive set of plans and actions directed at leveraging and shaping the sociopolitical and cultural institutions within an organization's external environment (Chris \& Mia, 2015). Thomas (2010) also described institutional strategies as the patterns of action 
that are concerned with managing the institutional structures within which firms compete for resources. Stating that the resources necessary to enact institutional strategy differ from those associated with competitive strategies because, institutional strategy demands the ability to articulate, sponsor and defend particular practices and organizational forms as legitimate or desirable, rather than the ability to enact already legitimated practices or leverage existing practices.

Chris and Mia (2015) conceptualized institutional strategy as the comprehensive set of plans and actions directed at leveraging and shaping socio-political and cultural institutions to maintain or improve an organization's competitive position. At its simplest, institutional strategy is a process that coordinates set of activities that shape strategic vision or help enact a firm's strategy. In other words it fuels emergent and planned strategies. Therefore, the key implication of the concept of institutional strategies is that firms are competing not only in terms of their ability to activate and exploit their existing resources but also in terms of their ability to renew and develop them (Micheal, Simon \& Jill, 2011). Although all organizational strategies occur within an institutional context. Institutional strategy is differentiated by its orientation to that context: simply put, institutional strategy is not so much concerned with gaining competitive advantage based on existing institutional structures as it is concerned with managing those structures, preserving or transforming institutional standards and rules in order to establish a strategically favorable set of conditions. Like other forms of organizational strategy defined as patterns of action, institutional strategies can be developed both deliberately as intended strategies, and unintentionally as emergent strategies (Mintzberg \& Waters, 1985).

\section{Institutional Performance}

Aremu and Oyinloye (2014) defined organizational performance as measuring the actual outputs or results against its intended (expected) outputs. Institutional performance, however, means different things to different institutions. Institution can use various parameters to measure performance. However, most MD institutions are for-no-profit and may use any of the following criteria for assessing their performance: number of employees, number of participants subscribing, number of market driven programs, physical expansion (liaison office), success of their programs, level of patronage, and financial sustainability among other parameters. Since improving the productivity of an institution is essential to its survival in the competitive world, the purpose of all productivity related endeavors is to bring about lasting improvements in the performance of management development institutions (Richard, 2009).

James, Grace, Patrick and Oluwatobilola (2015) view the concept of performance as a firm's idea based on the voluntary association of productive assets as human, physical, and capital resources, for the purpose of achieving set goals and create value. Therefore, organization could measure its performance using the financial measures which include profits, return on assets, return on investment and sales, and the non-financial measures which focus on issues pertaining to customer's satisfaction and customer's referral rates, delivery time, waiting time and employee`s turnover.

According to Muya and Wesonga (2012) performance is something which all institutions strive for, regardless of their size, because institutions want to get big, and big institutions want to get bigger. Therefore, institutions have to grow at least a bit every year in order to accommodate the increased training needs that emerge over time. He however added that performance is a broader indicator that should include productivity, quality, and consistency in service delivery. The researchers also established that institutional performance also means different things to different institutions. There are parameters an institution can use to measure its performance. If the primary goal of any business is profitability, such organizations will measure their performance in terms of net income, revenue, and other financial achievements. However, most government training institutions that are for-no-profit may use one of the following criteria for assessing their performance: number of staff, number of participants trained, number of market driven programs, physical expansion, success of their training programs, increased market share, financial sustainability among other parameters. Ultimately, success and performance of an institution will be gauged by how well an institution does relative to the goals it has set for itself (Richard, 2009).

\section{Institutional Theory}

Meyer and Rowan (1977); Powell and DiMaggio $(1983 ; 1991)$, Hinings and Greenwood (1988) have contributed to institutional theory discussion largely through the explanation of the processes by which legitimated forms of organizing become dominant within an organizational field. Central to institutional theory is its emphasis on the manner in which organizations adopt structures, procedures, or ideas based, not on efficiency, but rather on external definitions of legitimacy. Institutional theory is an important approach to shed some light in this issue, making more explicit the way some complexities are constructed within the organization, building practices not necessarily connected to efficiency goals, and having impact on innovative and performance initiatives. This theory considers the impact of the environment, the normative and regulative structures that surround the institutions. It attempts to explain how these structures impact the actions and boundaries of the institution. These structures provide stability to actions, routines and cultures; define legitimacy and constrain action. The theory focuses on how institutions are created, how they pervade societies and industries and finally how institutions change over time.

\section{Moderating Effect of Institution Policy on Institutional Strategies (IS) and Performance}

In another study by Elliott (2011), institutional choice of policy was used as one of the independent variables, evidence from Rwanda and Uganda, The researcher did a comparative analysis of two countries, Rwanda and Uganda, 
the exploratory results showed a strong support for theory whereby leaders allocate patronage in accordance with the kind of threats they face. Moreover, there was a positive significant relationship between institutional choice of policy and performance. Jose, Mohammad, Irani and Farhad (2011) researched on what is policy, social policy and social policy changing? the study found that aiming to approach the processes of social policy change in the construction of social development, the responsibility lies with the agents capable of promoting these changes, such as academics, researchers and analysts, civil society, technology information and communication technologies (ICTs) used by the media, and individual subjects of rights from holders. Earlye (2016) worked on policy structure and administration using exploratory method. The study reveals that institutional policies can be classified into three categories. These categories include the board of trustees' policies, the institution-wide policies and non-institution-wide policies. Also found out that institutional policies are supplemented by provisions of standards, procedures and process that are applicable to all institutional policies. The study therefore concluded that it is the responsibility of all employees and stakeholders to know and comply with these standards to enable improved institutional performance.

Institutional strategies have been measured in different forms in relation to its alignment of organizational change strategies and its relationship with increasing organizations performance. But Davood (2011) also carried out an investigation and the study was to find out the relationship between the alignments of different typologies of strategies for organizational change strategies (structure, technology, culture, human resources, and goals) with improving the performance by applying the qualitative and quantitative methods. It approved that: (1) The more the alignment among the typologies of organizational change strategies increases regardless of their group (high performance, medium performance, and low performance), the more their performance improves and (2) The more the alignment among the typologies of organizational change strategies increases in a specific group (low performance organizational group), the more their own performance improves. the results confirmed that there is a relationship between change variables (structure, human resources, technology, culture and goals) and strategic reference points with the performance (effectiveness and efficiency), and it has been a positive prospective, thus to improve organizational performance, first the strategic change variables need to be aligned with each other and then with the strategic reference points. Nandakumar, Abby, and Nicholas (2010) carried out a study that investigated the moderating effects of environmental and structural factors on business level strategy and performance. The results of the study indicate that the dynamics and hostility in the environment could act as moderating factors on the relationship between business level strategy and performance

\section{METHODOLOGY}

The survey research design was adopted for this study. It is advantageous to use this type of research design because it is commonly used in management and social sciences to collect and analyse data. This method is primarily concerned with the process and nature of this study. The adoption of this design is consistent with the studies of Isaac (2014), Mutemi, et. al., (2014) and Aremu, \& Oyinloye (2014). The correlation research design was used because it helps to determine the degree or level of relationship or association that exists between variables. Also, it allowed the researcher to examine and explain the association between the independent and dependent variables (Johnson, 2010).

This research design hybrid was necessitated by the understanding to verify formulated hypotheses that referred to the situation as stipulated in chapter one. Since the design of a research involves a specific framework within which a research study is to be conducted. This study, therefore, stated the research problems according to the literature reviewed along the identified problems (Agboola, 2014).

The target population for this research consists of all faculty staff and administrative staff in the various units in the selected five MDIs. The five MDIs are: Administrative Staff College of Nigeria (ASCON), Centre for Management Development (CMD), Agricultural and Rural Management Training Institute (ARMTI), and Public Service Staff Development Center (PSSDC) and Public Service Institute of Nigeria (PSIN). The selection of the five MDIs was made regardless of their location (states). The selection was further based on their long standing, in terms of training and performance since their time of establishment in Nigeria. West African Management Development Institute (WAMDEVIN, 2014). As shown in the Table 3.1 the total number of staff in the selected MDIs as at the time of this research was one thousand, three hundred and fourty four (1,344).

Table 3.1: List of five selected Management Development Institutions in Nigeria and their number of employees in various units.

\begin{tabular}{|c|c|c|c|c|c|c|}
\hline $\begin{array}{c}\text { S/ } \\
\text { N }\end{array}$ & $\begin{array}{c}\text { Names of } \\
\text { Management } \\
\text { Development } \\
\text { Institutions }\end{array}$ & $\begin{array}{c}\text { Num } \\
\text { ber } \\
\text { of } \\
\text { empl } \\
\text { oyees }\end{array}$ & $\begin{array}{c}\text { Numb } \\
\text { er of } \\
\text { Facult } \\
\mathbf{y} \text { Staff }\end{array}$ & $\begin{array}{c}\text { Numbe } \\
\mathbf{r} \text { of } \\
\text { Admini } \\
\text { strative } \\
\text { Staff }\end{array}$ & $\begin{array}{c}\text { Date } \\
\text { Reg. }\end{array}$ & Licensed \\
\hline 1 & ASCON & 415 & 125 & 290 & 1973 & $\begin{array}{c}\text { Act, cap. 6, } \\
\text { vol. 1 laws of } \\
\text { the } \\
\text { Federation of } \\
\text { Nigeria } \\
\text { (LFN) 1990 }\end{array}$ \\
\hline 2 & CMD & 303 & 105 & 198 & 1973 & $\begin{array}{c}\text { Act No 51 of } \\
1976 .\end{array}$ \\
\hline 3 & ARMTI & 182 & 81 & 101 & 1980 & $\begin{array}{c}\text { Act Cap. 11. } \\
\text { Vol.I LFN }\end{array}$ \\
\hline 4 & PSSDC & 83 & 30 & 53 & 1994 & $\begin{array}{c}\text { through Law } \\
\text { No.5 of 2013 }\end{array}$ \\
\hline 5 & PSIN & 361 & 147 & 214 & 2008 & \\
\hline & Total & 1,344 & & & & \\
\hline
\end{tabular}

Source: Researcher, (2017). 


\section{Sample Size and Sampling Technique}

The sample size for this study was determined by applying the Krejcie and Morgan (1970) table for sample size determination for categorical data. The sampling frame for this research work covers the employees at both the headquarters and liaison offices of the selected MDIs with the respondents being the heads of units, faculty staff and seniour administrative staff of the various units. This is necessitated because, among these employees are the decision makers (senior staff management committee) staff, the directors, principal officers, senior officers those involved in the day to day operations of the institutions but do not belong to the decision making level. Such officers are presumed to have had some good number of years of experience in that institution either as an administrative or faculty staff and are considered well informed of the operations and activities of their institutions.

Sample of 398 staff was selected from the five (5) MDIs with a significant level of 5\% and an error of $30 \%$. On the whole, 398 represents the number of respondents across the selected management development institutions (MDIs) to which copies of the questionnaire were administered. The sampling technique adopted for this study was multiple sampling techniques. This technique was used to eliminate the institutions that are not relevant to the focus of this study. This was considered appropriate because the population and location of research setting (MDIs) was known (Nwangangi, 2016).

\section{Method of Data Collection}

This study adopted the primary sources of data collection (questionnaire) in gathering data from the employees of the selected MDIs in Nigeria. This method was adopted to enable absolute and accurate capture of data from employees in the selected MDIs.

\section{Research Instrument}

The instrument for this study was a well-structured survey questionnaire. The items in the research instrument were adapted from existing questionnaire on related studies. The research instrument was used to capture personal data of employees on gender, age, marital status, highest educational qualification, designation, years worked in institution and job status. The instrument was also used to collect data on institutional strategies as the independent variable, while performance served as the dependent variable and the institutions policy (moderating) variables The study adopted the closed-ended questions using the modified six (6) Likert scale type.

\begin{tabular}{|c|c|c|c|c|}
\hline $\begin{array}{l}\mathbf{S} \\
/ \\
\mathbf{N}\end{array}$ & Variables & $\begin{array}{l}\text { Source of adapted } \\
\text { questionnaire }\end{array}$ & Validity & $\underset{\text { Reliabili }}{\text { ty }}$ \\
\hline & \multirow{2}{*}{$\begin{array}{l}\text { Institutional } \\
\text { policy (IP) }\end{array}$} & $\begin{array}{c}\text { Shelette, S (2002), Makinde, } \\
\text { O.G (2015) }\end{array}$ & Construct & $\begin{array}{l}0.898, \\
0.753, \\
0.711 \\
\end{array}$ \\
\hline & & $\begin{array}{c}\text { Madagamage, G.T., } \\
\text { Warnakulasooriya1, B.N. F., }\end{array}$ & Construct & 0.811 \\
\hline
\end{tabular}

\begin{tabular}{|c|c|c|c|}
\hline & $\begin{array}{c}\text { \& Wickramasuriya, H.V.A. } \\
\text { (2014). }\end{array}$ & & \\
\cline { 2 - 5 } & $\begin{array}{c}\text { Fatih. S, Masoodul .H, and } \\
\text { Zelal, A. (2011), } \\
\text { Zehir, C, Sehitoglu, Y, } \\
\text { Erdogan, E (2012) } \\
\text { Madagamage, G.T., } \\
\text { Warnakulasooriya1, B.N. F., } \\
\text { \& Wickramasuriya, H.V.A. } \\
\text { (2014). }\end{array}$ & Construct & 0.791 \\
& $\begin{array}{c}\text { Zafer, A. A., \& Pinar, A. } \\
\text { (2012) } \\
\text { Fatih. S, Masoodul .H, and } \\
\text { Zelal . A (2011). }\end{array}$ & $\begin{array}{c}\text { Construct } \\
\text { “ }\end{array}$ & 0.939 \\
\cline { 2 - 4 } & $\begin{array}{c}\text { Hishamuddin .F.A, Azleen.I, } \\
\text { Rahida, A.R \& Mohd .Z. A.R } \\
\text { (2008) }\end{array}$ & Construct & 0.952 \\
\hline
\end{tabular}

Sources of adapted questionnaire

\section{Research Instrument Source; Literature Review (2017)}

The above Table is indicating the sources of adapted questionnaire used in this study in line with the variables under study. According to Nunnaly (1978) an instrument is regarded to be reliable when the instrument has been subjected to validation through test-retest, internal consistency, content, construct and face validity and the cronbach alpha value is 0.7 or $70 \%$ and above. Since the values of the adapted questionnaires range from 0.711 to 0.952 as established by the original users of the instrument, it is therefore considered reliable for either adoption or adaption.

\section{Pilot Study}

The pilot study was conducted on two similar institutions such as. Nigerian Institute of Training and Development (NITAD) and Institute of Management Consultants of Nigeria (IMCON) being government approved training institutions within Lagos State, which are different from the institutions government established (public sector) training institutions that are the focus of this study. The pilot study was considered necessary in order to determine the willingness of the respondents, to have a foreknowledge of the reactions of the respondents and to ascertain the reliability of the questionnaire when used in an environment. An instrument is considered reliable if the cronbach alpha value of its scale is above .70 as recommended by Nunnally (1978).

\section{Validity of Research Instrument}

To ascertain the validity of the instrument, the research instrument was subjected to content and construct validity. The content validity was ascertained The construct validity of the measuring instrument was also established through confirmatory factor analysis to determine the covariance between the main construct and the items.

\section{Construct Validity of Instrument}

\begin{tabular}{|c|c|c|c|}
\hline S/N & Variables & $\begin{array}{c}\text { Number of } \\
\text { Items }\end{array}$ & $\begin{array}{c}\text { Average Variance } \\
\text { Explained }\end{array}$ \\
\hline 1 & Institutional policy (IP) & 8 & 0.809 \\
\hline \multicolumn{3}{|c|}{ Source: Researcher's Pilot Study (SPSS Output Result) } \\
\hline
\end{tabular}

Source: SPSS Output Result 
For construct and convergent validity of the research instrument, confirmatory factor analysis was used. The Average Variance Extracted (AVE) $>0.5$ was used. From the analysis average variance explained for the variable is greater than 0.5 , hence the construct validity of the variable involved in the study were therefore ascertained.

\section{Reliability of Research Instrument}

In order to test the reliability of the research instrument, the instrument was subjected to internal consistency method of reliability using $10 \%$ of the sample size, which are 40 respondents. The Cronbach's Alpha analysis was used to measure the internal consistency of the instrument. The instrument is considered reliable because, the cronbach alpha values of its scales were above 0.7 or $70 \%$. The Cronbach's Alpha results range from 0.733 to 0.923 .

\section{Model Specification}

$\mathrm{X}=$ Independent Variable

$\mathrm{Y}=$ Dependent Variable

$\mathrm{Z}=$ Moderating variables

Where:

$\mathrm{X}=$ Institutional Strategies (IS)

$\mathrm{Y}=$ Performance $(\mathrm{P})$

$\mathrm{Z}=$ Institutional policy (IP)

Where:

$$
\begin{aligned}
& \mathrm{X}=\left(\mathrm{x}_{1}, \mathrm{x}_{2}, \mathrm{x}_{3}, \mathrm{x}_{4}\right) \\
& \mathrm{x}_{1},=\text { Strategic Agility }(\mathrm{SA}) \\
& \mathrm{x}_{2}=\text { Strategic Flexibility }(\mathrm{SF}) \\
& \mathrm{x}_{3}=\text { Strategic Alliance }(\mathrm{SAL}) \\
& \mathrm{x}_{4}=\text { Strategic Planning }(\mathrm{SP}) \\
& \mathrm{Y}=\text { Level of patronage (LOP) }
\end{aligned}
$$

$\mathrm{Y}=\mathrm{f}(\mathrm{X}, \mathrm{Z})$ Functional

Equation

$\mathrm{P}=\mathrm{f}(\mathrm{IS}, \mathrm{IP})$

$\mathrm{IS}=(\mathrm{SA}, \mathrm{SF}, \mathrm{SAL}, \mathrm{SP})$

Therefore; $\mathrm{P}=\beta_{0}+\beta_{1}$ IS $+\beta_{2}$ IP $+\beta_{3}$ IS $*$ IP $+\mathrm{e}$ - Model of the study

Where:

P: Performance

IS: Institutional Strategies

SA: Strategic Agility

SF: Strategic Flexibility

SAL: Strategic Alliance

SP: Strategic Planning

\section{IP: Institutional Policy}

IS*IP = Interaction between Institutional Strategies and Institutional Policy

$\beta_{0}=$ constant of the equation or constant term

$\beta_{1-} \beta_{3}=$ Parameters to be estimated

$\mathrm{e}=$ error or stochastic term

\section{DATA ANALYSIS, RESULTS AND DISCUSSIONS OF FINDINGS}

Objective of this study was to examine the moderating effect of institutional policy on the relationship between institutional strategies and performance of MDIs. The respondents were requested to indicate how institutional policy moderates the relationship between institutional strategies and performance of MDIs on a six point Likert scale: Strongly Disagree $=1$, Disagree $=2$, partially Disagree $=3$, Partially Agree $=4$, Agree $=5$, Strongly Agree $=6$.

By combining responses under strongly agree, agree and partially agree, In addition, 311 respondents representing $88.9 \%$ agreed that all training programs were centrally regulated /controlled, while 38 of the respondents representing $10.9 \%$ disagreed. 310 respondents representing $88.6 \%$ agreed that the training policy was properly adhered to by the personnel department, while 39 of the respondents representing $11.1 \%$ disagreed. Finally, 330 respondents representing $94.3 \%$ agreed that rules/regulations were designed to guide staff, while 19 respondents representing $5.4 \%$ disagreed. Results in the above also show that the average mean of the responses was 4.75 , which stand for average of the respondents that agreed with the statements in the institutional policy questionnaire. The standard deviation was 1.163 meaning that the responses were clustered around the mean response. It suggests that the responses varied among the respondents.

\section{Restatement of hypothesis}

Ho: There is no significant moderating effect of institutional policy on the relationship between institutional strategies and performance of MDIs.

To test the hypothesis, Hierarchical regression was used. Data for Institutional strategies were created by summing responses of all items for strategic agility, strategic flexibility, strategic alliance and strategic plan, while data for performance of MDIs was created by summing responses of all items for level of patronage, participants' satisfaction, and the frequency of training by MDIs and data for institutional policy was generated by adding scores of responses of all items for the variable. 
Moderating Effect of Institutional Policy on the relationship between institutional strategies and performance of MDIs

\begin{tabular}{|c|c|c|c|c|c|c|c|c|c|}
\hline & & & & (a) Model s & mary & & & & \\
\hline \multirow{2}{*}{ Model } & \multirow{2}{*}{$\mathrm{R}$} & \multirow{2}{*}{ R Square } & \multirow{2}{*}{$\begin{array}{l}\text { Adjusted R } \\
\text { Square }\end{array}$} & \multirow{2}{*}{$\begin{array}{l}\text { Std. Error of the } \\
\text { Estimate }\end{array}$} & \multicolumn{5}{|c|}{ Change Statistics } \\
\hline & & & & & $\begin{array}{c}\text { R Square } \\
\text { Change }\end{array}$ & F Change & df1 & df 2 & $\begin{array}{l}\text { Sig. F } \\
\text { Change }\end{array}$ \\
\hline 1 & $.357^{\mathrm{a}}$ & .128 & .117 & 21.68237 & .128 & 12.304 & 4 & 336 & 0.000 \\
\hline 2 & $.388^{\mathrm{b}}$ & .150 & .138 & 21.43243 & .023 & 8.882 & 1 & 335 & 0.003 \\
\hline 3 & $.391^{\mathrm{c}}$ & .153 & .137 & 21.43456 & .002 & .933 & 1 & 334 & 0.335 \\
\hline
\end{tabular}

a. Predictors: (Constant), Strategic Plan, Strategic Agility, Strategic Alliance, Strategic Flexibility

b. Predictors: (Constant), Strategic Plan, Strategic Agility, Strategic Alliance, Strategic Flexibility, Institutional Policy

c. Predictors: (Constant), Strategic Plan, Strategic Agility, Strategic Alliance, Strategic Flexibility, Institutional Policy, Institutional Strategies*Institutional Policy (b) ANOVA $^{\mathrm{a}}$

\begin{tabular}{|c|c|c|c|c|c|c|}
\hline \multicolumn{2}{|r|}{ Model } & Sum of Squares & Df & Mean Square & $\mathrm{F}$ & \multirow{2}{*}{$\frac{\text { Sig. }}{0.000^{\mathrm{b}}}$} \\
\hline & Regression & 23137.387 & 4 & 5784.347 & 12.304 & \\
\hline & Residual & 157962.056 & 336 & 470.125 & & \\
\hline & Total & 181099.443 & 340 & & & \\
\hline & Regression & 27217.534 & 5 & 5443.507 & 11.850 & $0.000^{\mathrm{c}}$ \\
\hline & Residual & 153881.909 & 335 & 459.349 & & \\
\hline & Total & 181099.443 & 340 & & & \\
\hline & Regression & 27646.359 & 6 & 4607.727 & 10.029 & $0.000^{\mathrm{d}}$ \\
\hline & Residual & 153453.084 & 334 & 459.440 & & \\
\hline & Total & 181099.443 & 340 & & & \\
\hline \multicolumn{7}{|c|}{ a. Dependent Variable: Performance } \\
\hline \multicolumn{7}{|c|}{ b. Predictors: (Constant), Strategic Plan, Strategic Agility, Strategic Alliance, Strategic Flexibility } \\
\hline \multicolumn{7}{|c|}{ c. Predictors: (Constant), Strategic Plan, Strategic Agility, Strategic Alliance, Strategic Flexibility, Institutional Policy } \\
\hline & nstant), Strategic Plan & c Agility, Strategic & Strategic Flexibilit & Institutional Policy, I & nnal Strategies & ional Polic \\
\hline & & & Coefficients $^{\mathrm{a}}$ & & & \\
\hline & Model & & ized Coefficients & $\begin{array}{l}\text { Standardi } \\
\text { Coefficie } \\
\end{array}$ & $\mathrm{T}$ & Sig. \\
\hline & & B & Std. Error & Beta & & \\
\hline & (Constant) & 38.060 & 9.697 & & 3.925 & 0.000 \\
\hline & Strategic Agility & 0.314 & 0.260 & 0.076 & 1.207 & 0.228 \\
\hline 1 & Strategic Flexibility & 0.741 & 0.319 & 0.164 & 2.321 & 0.021 \\
\hline & Strategic Alliance & 0.473 & 0.308 & 0.104 & 1.537 & 0.125 \\
\hline & Strategic Plan & 0.636 & 0.297 & 0.119 & 2.140 & 0.033 \\
\hline & (Constant) & 31.578 & 9.829 & & 3.213 & 0.001 \\
\hline & Strategic Agility & 0.294 & 0.257 & 0.071 & 1.144 & 0.253 \\
\hline 2 & Strategic Flexibility & 0.535 & 0.323 & 0.119 & 1.658 & 0.098 \\
\hline & Strategic Alliance & 0.236 & 0.314 & 0.052 & 0.750 & 0.454 \\
\hline & Strategic Plan & 0.446 & 0.301 & 0.083 & 1.484 & 0.139 \\
\hline & Institutional Policy & 0.653 & 0.219 & 0.186 & 2.980 & 0.003 \\
\hline & (Constant) & -19.641 & 53.920 & & -0.364 & 0.716 \\
\hline 3 & Strategic Agility & 0.724 & 0.514 & 0.175 & 1.409 & 0.160 \\
\hline 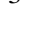 & Strategic Flexibility & 0.976 & 0.559 & 0.217 & 1.746 & 0.082 \\
\hline & Strategic Alliance & 0.713 & 0.586 & 0.157 & 1.217 & 0.224 \\
\hline
\end{tabular}




\begin{tabular}{|c|c|c|c|c|c|}
\hline Strategic Plan & 0.904 & 0.561 & 0.169 & 1.611 & 0.108 \\
\hline Institutional Policy & 2.054 & 1.466 & 0.584 & 1.401 & 0.162 \\
\hline Institutional Strategies*Institutional Policy & -0.012 & 0.013 & -0.623 & -0.966 & 0.335 \\
\hline
\end{tabular}

Source: Field Survey Results, 2017

The Table presents the summary of the moderating effect institutional policy has on the relationship between institutional strategies and performance of MDIs. The results show that the correlation coefficient $(\mathrm{R})$ between institutional strategies and performance of MDIs is 0.357 , when the parameter of institutional policy was added, the model increased to 0.388 , and with addition of the parameter of the interaction of institutional strategies and institutional policy it further increased to 0.391 . However, the results reveal that the relationship between performance of MDIs, institutional strategies, and institutional policy is weak. The results indicate further that there are different variations in performance of MDIs accounted by institutional strategies and institutional policy. The coefficient of determination, $\mathrm{R}^{2}=$ 0.128 shows that $12.8 \%$ of the variations of performance of MDIs have been explained by the variables of institutional strategies, institutional policy and the interaction of institutional strategies and institutional policy. The remaining $87.2 \%$ of the variations are explained by other factors, which are not part of this study. The interpretation is that the regression model for the institutional strategies does not have a good fit. When parameter of institutional policy is added, the change of the coefficient of determination $\left(\Delta \mathrm{R}^{2}\right)$ reduces by $2.3 \%$. With a further addition of the parameter of the interaction of institutional strategies and institutional policy the percentage of variability accounted for reduction to 0.002 $\left(\Delta \mathrm{R}^{2}\right)$.

The regression equation explaining the result of the analysis is expressed as follows;

$\mathrm{P}=\beta_{0}+\beta_{1}$ IS $+\beta_{2}$ IP $+\beta_{3}$ ISIP $+\mathrm{e}: \ldots \ldots \ldots \ldots$

Performance $=-19.641+0.175 \mathrm{SA}+0.217 \mathrm{SF}+0.157 \mathrm{SAL}+$ $0.169 \mathrm{SP}+0.584 \mathrm{IS}-0.623 \mathrm{IS} * \mathrm{IP} \ldots$... Equation

The corresponding F-ratio for the model are institutional strategies was $12.465[\mathrm{~F}(4 / 336)=12.465]$. When the parameter of institutional policy was added, the change in Fratio is $8.882[\mathrm{~F}(4 / 336)=11.850]$; with a further addition of the parameter of the interaction of institutional strategies and institutional policy the change in F- ratio was $0.933[\mathrm{~F}(4 / 336)$ $=12.465]$. The corresponding $\mathrm{p}$-value for the model, institutional strategies is significant $(\mathrm{p}<0.05)$, institutional policy is significant at $5 \%(\mathrm{p}<0.05)$, but the interaction of institutional strategies and institutional policy in Model 3 is not statistically significant $(p>0.05)$. The results, therefore, show that institutional policy has no statistically significant moderating effect on the relationship between institutional strategies and performance of MDIs. Therefore, the null hypothesis $\left(\mathrm{H}_{0}\right)$ which states that there is no significant moderating effect of institutional policy on the relationship between institutional strategies and performance of MDIs cannot be rejected.

\section{Discussion}

The test of hypothesis was to ascertain whether institution policy has any moderating effect on the relationship between institutional strategies and performance of the selected MDIs in Nigeria. The results showed that institution policy has no statistically significant moderating effect on the relationship between institutional strategies and performance of MDIs. The corresponding F-ratio for the model are institutional strategies was $12.465[\mathrm{~F}(4 / 336)=12.465]$. When the parameter of institutional policy was added, the change in Fratio was $8.882[\mathrm{~F}(4 / 336)=11.850]$; with a further addition of the parameter of the interaction of institutional strategies and institutional policy the change in F- ratio was .933 [F(4/336) = 12.465]. The corresponding $\mathrm{p}$-value for the model, institutional strategies is significant $(\mathrm{p}<0.05)$, institutional policy is significant at $5 \%(\mathrm{p}<0.05)$, but the interaction of institutional strategies and institutional policy in Model 3 is not statistically significant ( $p>0.05)$.

The finding is in consonance with the findings of Jose, Mohammad, Irani, and Nezhad (2013) that despite lots of good researches that have been done regarding institutional policy, there are still issues and therefore, lack of help and interest for the development of institutions policy. Various researchers such as Makhoul, 2005; Leviten-Reid 2004; and Sherri (2005) have also argued that institutional policy is inconclusive in nature in that there is no simple way to address it and perhaps that is why some employees claim to have little or no understanding of policy. In fact, some would claim that it has little or no relevance to their work. The result also agreed with Michael, Simon and Jill (2011) study which asserted that the 'what, how, who, and why' represent the four aspects of the policy process. But we believe that, for each of these aspects, recent reforms have failed to address the realities of policy making. The attempts to improve policy making have all suffered from a gap between theory and practice. Either they have presented unrealistic models of policy making, or have failed to provide the support to turn desired practices into reality. Therefore, its insignificance can be attributed to focus on issues that are key or of much concern to the selected MDIs.

Furthermore, Earlye (2016) work on policy structure and administration using exploratory method. The study revealed that institutional policies can be classified into three categories. These categories include the board of trustees' policies, the institution-wide policies and non-institution-wide policies. Earlye study found out that institutional policies are 
supplemented by provisions of standards, procedures and process that are applicable to all institutional policies. The study, therefore, concluded that it is the responsibility of all employees and stakeholders to know and comply with these standards to enable improved institutional performance. Jose, Mohammad, Irani and Farhad (2011) researched on what policy is; social policy and whether social policy changing? The study found that aiming to approach the processes of policy change in the construction of institutions development, the responsibility lies with the agents capable of promoting these changes, such as academics, researchers and analysts, civil society, technology information and communication technologies (ICTs) used by the media, and individual subjects of rights from holders. Nandakumar, Abby, and Nicholas (2010) carried out a study that investigated the moderating effects of environmental and structural factors regarding institution policy on business level strategy and performance. The results of the study indicate that the dynamics and hostility in the environment could act as moderating factors on the relationship between business level strategy and performance.

However, the result that institution policy plays no statistical significant moderating effect on the relationship between institutional strategies and performance of the selected MDIs in Nigeria might not be significant. But since policy represents a decision made by a designated body, deemed to be in the public interest. After considering varied options, and the potential resultant effect of various factors. Regarding the following; who benefits from the policy, who stands to be negatively affected, time needed for, and to implement for solution, cost implication, funding and the political dynamics of the ruling government and structure, it could be likened to Jose, Mohammad, Irani and Farhad (2011) that aiming to approach the processes of policy change in the construction of institutions development, the responsibility lies with the agents capable of promoting these changes. Whereby in this case of MDIs, the office of the Head of service is responsible. This was also indicated in 310 respondents representing $88.6 \%$ agreed that the institution's training policy was properly adhered to by the personnel department. This study, however, concluded that the strength of policy making in any institution is integral to the strength of government as a whole, and that of the country at large.

\section{CONCLUSION AND RECOMMENDATIONS}

This study examined the moderating effect of institution policy on the relationship between institutional strategies and performance of the selected MDIs in Nigeria.. The results of the analysis show that institutional policy has no statistically significant moderating effect on the relationship between institutional strategies and performance of the selected MDIs in Nigeria. $\mathrm{R}^{2}=0.002, \mathrm{~F}_{(4 / 336)}=0.933,(\mathrm{p}>0.05)$.

Based on the findings of the study, the following recommendations are to be considered and addressed by the relevant authorities such as the senior management committee, top management committee of MDIs in Nigeria and the Nigerian government.

Recognizing the role and importance of MDIs in economic development, government (the office of the head of civil service of the federation) should develop flexible and concise policies as means of institutional support. When policies are understood by the different entities in an institution, there will be an atmosphere of improved performance reason being that everyone will work according to stipulated rules, using their initiative for creative value within the stipulated strategies. Though insignificant in this study, yet it should be understood by the employees of the MDIs as this will go a long way to ensure that the practice of institutional strategies will definitely enhance the performance level of the MDIs in Nigeria. This study therefore suggest further research be carried out in relation to effect of policy on institutional performance.

\section{REFERENCES}

[1] Administrative Staff College of Nigeria (ASCON), (2009). Annual report.

[2] Administrative Staff College of Nigeria (ASCON), (2010). Annual report.

[3] Aremu, M. A., \& Oyinloye, O. O., (201 4). Relationship between strategic management and firms' performance in Nigerian banking industry. Kuwait Chapter of Arabian Journal of Business and Management review 14(3)

[4] Awais, J. \& Asma, I. (2013). Perception of glass ceiling in the educational. institution: An evidence from Pakistan. World Applied Sciences Journal 23 (5), 628-634. DOI: 10.5829/idosi.wasj.2013.23.05.717

[5] Bureau of Establishments, Management Services and Training Office of the Head of Service (2011). Human resources development policy, Kaduna State Government.

[6] Chris. M., \& Mia. R. (2015). Institutional strategies in emerging markets. The Academy of Management Annals, 9(1), 291-335.

[7] Davood, S. (2011). Alignment of organizational change strategies and its relationship with increasing organizations' performance. Procedia Social and Behavioral Sciences 20, 1099-1107.

[8] Earlye, J., (2016) Policy structure and administration, Institutional Policy (IP) Palmer College of Chiropractic Davenport, Iowa.

[9] Elliott, G. (2011). Patronage as institutional choice: Evidence from Rwanda and Uganda.

[10] Eniola, A. A., Entebang, H., \& Sakariyau, O. B. (2015). Small and medium scale business performance in Nigeria: Challenges faced from an intellectual capital perspective. International Journal of Research Studies in management, 4(1), 59-71

[11] Georg. W., Erkki, L., Gillian, M., \& Leif, K. (2007). Improving knowledge transfer between research institutions and industry across Europe: Embracing open innovation .Luxembourg: Office for Official Publications of the European Communities, 36.

[12] Institute for Government analysis of capability reviews, which are available http://www.civilservice.gov.uk/about/improving/capability/index.a spx $22^{\text {nd }}$ February, 2017.

[13] Isaac, (2014). Algorithms and computation: 25th International Symposium, Jeonju,Korea 15 - 17December proceedings.

[14] James, U. M., Akinola, G. O., Ologbenla, P., \& Aladeraji, O. K. (2015). Strategic management and firm performance: A study of selected manufacturing companies in Nigeria. European Journal of Business and Management, 7(2), 12-32.

[15] Johnson, S. L. (2010). Research and statistics: A question of time, Cross-sectional versus longitudinal study designs. Pediatrics in Review, 31, 250-252.

[16] Jose, V. H., Mohammad, R. N., Irani, F., \& Farhad, N. H. A. (2013). What is policy, social policy and social policy changing? 
International Journal of Business and Social Science, 2(10), 287291.

[17] Leviten-Reid, E. (2004). Reflections on Vibrant Communities. Ottawa: Caledon Institute of Social Policy.

[18] Makhoul, A. (2005). Assured Income for the Severely Handicapped Public Policy Initiative. Ottawa: Caledon Institute of Social Policy.

[19] Makinde, O. G. (2015). Strategic planning and performance of small and medium enterprises (SMEs) in Lagos state, Nigeria. Unpublished thesis of Doctor of Philosophy Degree (Ph.d) in Business Administration , Strategic Management in the Department of Business Administration and Marketing, Babcock Business School, Babcock University, Ilishan-Remo, Ogun State, Nigeria.

[20] Micheal, H., Simon, P., \& Jill, R. (2011). Policy making in the real world evidence and analysis. Retrieved $22^{\text {nd }}$ February, 2017 from http://www.civilservice.gov.uk/my-civil-

service/networks/professional/policy-profession/policy-skillsframework.aspx

[21] Michael, H., Simon, P. \& Jill, R. (2011). Policy making in the real world, evidence and analysis. Institute for Government. https://www.instituteforgovernment.org.uk/sites/default/files/publi cations/Policy\%20making\%20in\%20the\%20real\%20world.pdf

[22] Muya, J. N., \& Wesonga, J. N. (2012). The impact of organisational culture on performance of educational institutions. International Journal of Business and Social Science, 3(8), 12-25.

[23] Nandakumar, M.K., Abby, G. \& Nicholas, O. R. (2010) "Business-level strategy and performance: The moderating effects of environment and structure", Management Decision, 48(6), 907939, https://doi.org/10.1108/00251741011053460

[24] Nwangangi, P.W. (2016). Influence of logistics management on performance of manufacturing firms in Kenya. An Unpublished $\mathrm{PhD}$ thesis of Jomo Kenyatta University of Agriculture and Technology, Kenya.

[25] Ojokuku, R. M., \& Adegbite, T.A. (2014). The impact of capacity building and manpower development on staff performance in selected organisations in Nigeria. International Journal of
Economics, Commerce and Management United Kingdom, 5(6), 23-38.

[26] Onyema E. O., \& Akanbi P.A. (2012). The influence of strategic agility on the perceived performance of manufacturing firms in Nigeria. International Business and Economic Research Journal, 11(2), 11-23.

[27] Oyedijo, A. (2012). Strategic agility and competitive performance in the Nigerian telecommunication industry: An empirical investigation. American International Journal of Contemporary Research, 2(3), 23-47.

[28] Oyedijo, A. (2013). Business Policy and strategic management ( $2^{\text {nd }}$ ed.). Ikeja: Strategic International Press Ltd.

[29] Policy Based- Management (2011). What is com available on line at: http://whatis.techtarget.com/definition/0,,sid9_gci537241,00.html

[30] Rahimi, G. R. N., \& Mohammad, R. (2011). A glance on policy, social policy making process and its related issues, Res Managerial, May issue (forthcoming).

[31] Richard, F. (2009). Strategic planning and the Nigeria University system innovation project discussion paper. Nigeria University System Innovation Project (NUSIP).

[32] Sherri, T. (2005). What is strategy? The Caledon Institute of Social Policy Ottawa, Ontario, Canada, 42-49.

[33] Thomas, B. L. (2010). Institutional strategy at simonfraser library on http://jom.sagepub.com/cgi/content/abstract/25/2/161

[34] Thomas,B. L. (1999). Institutional strategy: Journal of Management, 25(2), 161-188.

[35] Weber, Y. Junni, P., Sarala, R., \&Tarba, S. (2015). The role of strategic agility in acquisitions. British Journal of Management, 26(4), 596-616.

[36] West African management development institute (WAMDEVIN), (2016).

[37] Zhao, C., Qian, H., Hefu, L., Robert, M. D., \& Liang, L. (2014). Developing organizational agility through IT capability and KM capability: The moderating effects of organizational climate. Management Decision, 51(7), 1442-1461. 